\author{
Rinelle Evans
}

\title{
The impact of presenter speech personality on learner participation during televised instruction
}

\begin{abstract}
A B S T R A C T Interaction between educator and learners is widely considered crucial for effective instruction. The TeleTuks Schools community project involved several hundred learners watching daily broadcasts that aimed to offer academic support to matriculants via interactive television (ITV). While technology permitted bi-directional audio contact with the presenter in the studio, Grade 12 viewers seldom phoned in to ask questions or make comments about the content being presented on screen. These infrequent responses were unexpected and called for explanation. An initial proposition suggested that learners lacked sufficient proficiency in the medium of instruction - English and thus refrained from participating. Methods used for data gathering included analyses of telelessons, learner and adult interviews and open-ended survey questions. Findings revealed that limited English was not the primary cause of low responsiveness but rather a combination of presenter-related factors. This paper focuses specifically on presenters' speech personality, speed of delivery, immediacy behaviours and questioning styles. These constructs have contributed to the formulation of an instructional dissonance theory and recommendations are deemed applicable to any face-to-face instructional contexts as well as blended learning environments where verbal interaction is prevalent.
\end{abstract}

Keywords: interactive television, instructional dissonance, interaction, poor learner responsiveness, presenter dominance

\section{Introduction}

Why do learners refrain from asking questions during instructional broadcasts even though technology allows for synchronous, oral presenter-viewer interaction? This question, born in studio corridors, is the principal thrust of this research effort. 
Since the inception, of the TeleTuks ${ }^{\mathbf{1}}$ Schools project initiated in 1994 by the University of Pretoria (UP), South Africa, informal feedback by the teleteachers indicated that learners were not interacting freely with the presenter during broadcasts. Despite several measures taken to encourage participation e.g. offering incentives to phone in as well as limiting possible technological intimidation by explaining how the equipment works, the level of interaction did not increase. As presenters were uncertain why viewers were not phoning in, concerns started growing that no one was actually even watching the lessons. I knew that although my institution was a local pioneer in technologically supported learning, we did not have the same sophisticated equipment that is available in some of the industrialised countries and certainly nothing comparable to multi-site linkages and two-way video channels. Yet this alone could not have accounted for the poor responses. Previous personal experience of using television as an instructional delivery mode to remote adult learners mirrored the current phenomenon of poor viewer participation. The project team's expectations had been that young learners would be less inhibited and eager to phone in. The traditional transactional model of communication customarily used in face-to-face education environments was not in tune with this context. The expected learner feedback did not follow after presenter-initiated questions. So what was hampering the communication process during televised lessons? My hunch was that the learners' English proficiency was too limited for them to engage publicly with the presenter on air and as project manger I thus conducted a pilot study during July 2001 to establish more accurately why learners were not interacting as expected. Questionnaire data indicated that $96.6 \%$ of the respondents had never interacted with the presenter. This initial investigation was later formalised as a doctoral case study that sought to explain poor learner-presenter interaction during televised instruction, even though the supporting technology permitted bi-directional audio links. In this article I present an extract of the full inquiry highlighting the influence of the presenters' speech personality on learner participation.

\section{Contextualising the study}

During the research period (2001-2004), broadcasts were beamed via digital satellite to 72 schools that had been appropriately equipped using sponsorship money. These schools are primarily located in underdeveloped rural areas of four of South Africa's inland provinces although some township schools ${ }^{2}$ also participated. Schools in the remaining five provinces were not equipped purely for logistical reasons.

The intention of the project was 'not to replace educators at schools, but to assist learners with quality education in the more difficult aspects of the subjects' (Sedibe \& Evans, 1999: 2). The lessons were generic and aimed to review, rather than introduce new content. Logistics, however, prevented printed support material being offered. This initiative was aimed at Grade 12 senior secondary school learners (aged 17-19), who watched 90-minute lessons in key subjects, for

1 TUKS is the original name of the university given in 1908 (Transvaal Universiteitskollege) and the nickname by which the institution is commonly known in popular parlance. The alliterative link was deemed an appropriate name for the institution's instructional television channel.

2 Township schools - a legacy of the Apartheid education policy - serve Black peri-urban settlements. Historically the composition of the South African population has been based on race classification and although not comfortable with this appellation I use this categorisation (capitalised and not as an adjective) to clarify the particular ethnic group as prime target audience. 
example Mathematics, Physical Science and English, four afternoons a week of the academic year. An average of 30 hours per academic subject was screened annually and the national core syllabus was the main guide to planning lesson content.

The primary mode of content delivery during each TeleTuks broadcast alternated between traditional 'talking head' explanations and any visual material the presenter used to clarify concepts. A key feature, however, which distinguished these learning opportunities from similar educational projects, was that learners could ask questions at any time during a broadcast to which the presenter would then respond immediately. This bi-directional audio communication during a broadcast was established telephonically. The learner's phone call was fed into the studio while the presenter's response was transmitted directly on-air using a microphone. No multi-site audio or video linkages existed. Direct interaction was sought through presenterinitiated questions as part of the instructional design or during a planned Question-and-Answer slot. At times, learners were requested to solve problems or discuss options with a classmate. While completing such tasks, the presenter's image would be blanked out by the University logo and background music played. An invitation to call in to the studio with comments or queries was also regularly crawled across the screen as a chiron. Phone calls or faxes received after the broadcast were dealt with during the subsequent session. This ability to interact was used as a marketing ploy of the project based on the widely accepted premise that interaction improves learning. However, presenters continued to be puzzled by the observation that in spite of the technological system that allowed for two-way audio communication and thus oral interaction, learner participation - as anticipated by the project team - remained exceptionally low. An interaction rate of $0.27 \%$ per 60 -minute broadcast was calculated using broadcast logs and analyses. This was in stark contrast to other studies that had viewer responses every two to four minutes. (Lyons, MacBrayne, \& Johnson, 1994; McHenry \& Bozik, 1995; Oliver \& Grant, 1995). Such active participation elsewhere heightened the rarity of responses in my context.

It needs to be stated that unlike many studies discussed in the literature (Edirisingha, 1999; Fulford \& Zhang, 1993; Shrestha, 1997), the TeleTuks presenters had no participants at the origination site and when talking to the camera, visualised a group of approximately 30 learners at the various remotes sites. The size of such groups would be considered average in the South African context but large by comparison to the developed world. Even more so, if it is taken into account that potentially several hundred viewers watched the broadcasts simultaneously. The project team had envisaged a potential audience of several thousand Grade 12 viewers per daily broadcast. It was also the potential size of the viewer audience that had created the expectation of greater learner participation.

\section{Methodology}

I position myself within the interpretivist paradigm which posits that social reality is but a network of assumptions and intersubjectively shared meanings (Burrell \& Morgan, 1979). Working within this theoretical framework, I endeavoured to make meaning of the behaviour of the participants and enhance my understanding of their ITV experiences.

This study investigated the TeleTuks Schools community project as a clearly defined unit of analysis. An extensive study of current literature related to instructional television presented the conceptual parameters within which the study was located, and identified lacunae in the 
knowledge base. The formulation of the research question favoured a case study method that allowed for an investigation and a holistic description of participants' real-life experience of interactive television in context. The primary informants were nine subject experts who presented telelessons, close on 300 Grade 12 viewers and five site educators. I was a participant observer in this inquiry. I undertook fieldwork at several sites; chiefly those related to the participants' immediate context, i.e. learners were interviewed in groups at school and presenters at the studio facilities. Telephonic interviews were conducted with educators. Since the data gleaned during the pilot study in 2001 had not suggested a key explanatory variable, I selected a multiplicity of data sources and collection methods in order to establish more accurately factors that may be inhibiting oral interaction during a televised lesson. I used a small-scale quantitative approach based on a questionnaire survey and phone call log (percentages) in order to establish how prevalent poor participation is, while a more personalised experience obtained by means of interviews and an analysis of recorded broadcasts generated qualitative data which suggested reasons why learners refrained from interacting. My initial plan had been to execute a structured content analysis of the broadcasts. However, after an analysis of the telelessons, it became evident that the level of presenter-initiated interaction was too low to produce reliable data and I changed strategy to conduct a global evaluation of the televised learning event with special reference to the instructional design and communication skills, as well as pedagogical principles.

I prepared all transcripts and narrative responses for electronic scrutiny and a rigorous data analysis process was facilitated by using Atlas.t $i^{\mathrm{TM}}$. The search for relationships or patterns, silences or unexpected trends all formed part of the continuous analysis and interpretation of data. I visually illustrated emerging patterns for ease of interpretation using tables and network maps. Findings emerging from this study have answered the research question and added new understandings of why viewers refrained from interacting during telelessons.

\section{Findings related to presenters' speech personality}

I share the view that teaching is a communication art (Main \& Riise, 1995). In any instructional episode, the primary message being conveyed is the content of the subject material and generally the initiator of this communicative act is the instructor (ITV presenter). I also accept the interdependent relationship between source and receiver as described in the classical work of Berlo (1960) and thus it follows that the presenter and viewer must both play an active role in the process of making meaning. In terms of the TeleTuks project, the nature of television as a mono-directional communication channel complicated the encoding and decoding of the instructional message considerably. The lack of visual feedback hindered the interactive process and presenters in particular, experienced a sense of disconnectedness from the viewers with whom they were communicating. Feedback on the sender's message thus appears to extend beyond mere words and includes subtle non-verbal clues that learners have comprehended the message. However, despite some technical limitations, interaction during telelessons appeared to be constrained more by factors linked to presenter-as-initiator-of-communication rather than learner inhibitions or linguistic shortcomings as initially thought.

Human speech is characterised by unique individual modes of expression. These idiosyncratic, distinctive qualities relate to vocal traits as well as expressive verbal skills and make up what Hyde (1979) terms an individual's speech personality. Most of the presenter evidence emerged 
during the research process as viewers described their experience of watching the broadcasts. Comments about speed of delivery and lack of opportunities to ask questions made me focus more pertinently on the presenters' communication skills. I noted their tone of voice, volume, idiolect, the level at which they pitched their communication and how frequently they created opportunities for interaction. Other aspects included accent, fluency (speech rate), accuracy, and whether they used inclusive, invitational language. I forthwith provide a concatenation of evidence by drawing on survey and interview data as well as asynchronous analyses of videotaped broadcasts.

\section{Presenter profile}

Five of the eight persons interviewed were native speakers of English although the other three had native tongue proficiency in their second language; noticeable primarily in accent and at times linguistic slips e.g. write legitimately instead of legibly. I present as detailed a profile of the presenters as research ethics permit in order to maintain anonymity in Table 1.

Table 1: Presenter profile

\begin{tabular}{|cccclc|}
\hline $\begin{array}{c}\text { Subject } \\
\text { presenter }\end{array}$ & Gender & Age* & $\begin{array}{c}\text { Period of } \\
\text { involvement }\end{array}$ & Academic background & $\begin{array}{c}\text { Mother } \\
\text { tongue }\end{array}$ \\
\hline 1 & F & $40+$ & $2002-2004$ & Secondary school teacher & Afrikaans \\
\hline 2 & F & $60+$ & $1996-2002$ & Higher education & English \\
\hline 3 & F & $45+$ & $1997-2002$ & $\begin{array}{l}\text { Secondary school teacher/ } \\
\text { part-time lecturer }\end{array}$ & English \\
\hline 5 & F & $45+$ & $1997-2001$ & Private tutor & English \\
\hline 6 & M & $55+$ & $1996-1998$ & Higher education & Afrikaans \\
\hline 7 & F & $30+$ & 2002 & Secondary school teacher/ & English \\
\hline 8 & F & $60+$ & $2001-2004$ & Private tutor & English \\
\hline 9 & M & $30+$ & 2002 & Higher education & Tswana \\
\hline $10 * *$ & F & $40+$ & 2002 & Higher education & English \\
\hline
\end{tabular}

* increments of 5 years

Presenters were keen to participate in this project and managed to stay enthusiastic although personal and professional commitments did result in two presenters withdrawing after only a few broadcasts. Although gender and racial representation may not have been favourable, the collective teaching experience of the presenters was notable.

\section{Clarity and speed of explanations}

The presenter - as a key participant in the instructional process - was rated highly by a large proportion of the learners $(63.5 \%)$ who felt that they did not need to ask a question as the presenter explained everything well. Respondent 102 endorsed this view with: The presenter teach [sic] in a way that we can understand. They are not fast so I am never left behind. 
Respondent 16 also reiterated support of clear explanations by commenting that the teaching and the explaining is enogh [sic] to make me to understand the work. Other remarks of praise included:

- ... I understand well more especially she/he uses some diagram [sic] to show what she/he explains (R23).

- Helthey [presenters] explain quite adequately, enough to satisfy my knowledge (R31).

- Everything the lecture [sic] explains, it is clear and understandable (R32).

However, these complimentary comments about the presenter did not tally with more than a third of the viewers $(36.5 \%)$ who felt that the presenter did not explain well. Viewers, who shared this view, specifically highlighted the speed of delivery. As Respondent 48 stated: In Maths lessons the teacher was too fast. Even in English we also could not write important notes cause of fastness. While Respondent 36 also experienced frustration because the presenter is too fast so I have lots of questions in a little [sic] time. Another added: I would like to have the mathematics video cassette to watch it again at home cause somewhere the presenter was too fast (R21). At site \#3, a learner explained that: Sometimes for me it is difficult when the presenter is presenting on the TV because I don't even understand. We... we... I was not... eish ${ }^{3 !}$ I don't... don't know what can I say... (loud laughter from peers) the... the presenter presenting on the $T V$, he or she is fast, that's why I don't understand.

He was supported by Respondent 68 who stated that I do not understand because I don't have inof [sic] time to ask. Respondent 41 politely endorsed this view: I would say that [the winter school] is nise [sic] but I don't understand anything that they taught use [sic] because the presenter was too fast and we didn't have time to ask questions. After being encouraged to use his mother tongue, an urban learner from site \#1 wryly added: The presenter when he presents the lesson he goes like we are watching a movie and not like a teacher in a class. Upon concluding an interview, a rural learner raised his hand saying: II [sic] have a qu-question and I just want to know if we can try to to [sic] tell the the [sic] presenter to be slow as sometimes they they [sic] are fast (pause)... and if they can try to to [sic] decelerate [sic] their speed sometimes we can understand too. Despite his speech impediment this learner had sufficient confidence to talk to me in front of his peers without my having elicited a response suggesting that in his case, the reason for not interacting was unrelated to inhibition but rather external factors. Another suggestion made by an exasperated learner was: At least those teachers must try to come to our schools so that it can be simple for us to stop him/her when we don't understand. On TV they are teaching fast so we can't exactly understand (R08/01).

In order to establish whether presenters were in fact speaking too fast, I calculated the speed of their spoken English during televised instruction and present it in Table 2.

Using a manual stopwatch, I recorded the introductory section of a broadcast from the actual video recordings and then transcribed it into text, whereafter I ascertained the number of words per minute using the word count function in Microsoft Word ${ }^{\mathrm{TM}}$. An average of seven minutes offered a comprehensible chunk of English with sufficient context. The average number of words per minute for a mother tongue speaker of English is set at 125-145 words per minute

3 Typical Black South Africanism used to express a variety of emotional responses e.g. shock, surprise and in this case embarrassment. 
Table 2: Rate of spoken English per presenter

\begin{tabular}{|cccc|}
\hline Presenter & Recorded time & Words in chunk & Words per minute \\
\hline 1 & $6: 50$ & 881 & 130 \\
\hline 2 & $7: 30$ & 1090 & 145 \\
\hline 3 & $7: 28$ & 1001 & 134 \\
4 & $6: 31$ & 763 & 117 \\
5 & $6.23^{*}$ & 1004 & 181 \\
6 & $6: 30$ & 767 & 118 \\
7 & $6: 40$ & 771 & 116 \\
8 & $7: 30$ & 868 & 116 \\
9 & $7: 10$ & 1199 & 167 \\
\hline
\end{tabular}

(Du Plooy-Cilliers \& Olivier, 2001; Monson, 1978; Zhang \& Fulford, 1994 ). Only two presenters were markedly fast, four spoke slower than the average rate while the other three presenters had an acceptable rate of spoken discourse. However, what was audibly manifest was that presenters did not pause between statements thus not allowing for time in which learners could process the input aurally and cognitively. Sequences were linked solely by inhalation of air and the illusion of speed was intensified by inadequate verbal signposting. More silence in an explanation and the improved use of transitions e.g. Here are two points: Firstly ... The second point is ... rather than a slower speech rate would have facilitated comprehension. Some presenters were also unnecessarily verbose; further complicating matters for a second language learner who had to process all the English and then still distinguish between vital and extraneous information as illustrated here:

We will now do question 5 of last year's national exam and that comprises logarithms. Now logarithms, again you have to know a few ... hmmm ... formulae, you have to know a few definitions and then honestly I think that everybody and anybody can and should love doing logarithms. See if you agree with me. Let's read our first question now. It says here that: Showing, show without using a calculator, very importantly, do not use a calculator, that 1 plus etc. Now let's quickly rewrite it and then again, as always, there is no room for spectators in mathematics. You have to do this with me. $1+4 x \log$ of $3 . .$.

Not only the perceived speed at which presenters explained but also their verbosity, insufficient word bridges and pausing elucidates the disconcertingly high percentage (70.5\%) of Grade 12 viewers who felt that they had not understood everything.

\section{Lack of opportunity to ask}

Presenters apparently did not always create the opportunity for viewers to call in as both Respondents 63 and 78 alleged: She did not give us a chance to phone in and The presenter did not give me a chance to ask question [sic]. Everything in winter school was just fine but I was desponded [sic] because we didn't have a chance to ask questions. Some presenters admitted neglecting to create opportunities for real-time interaction. 


\section{Type of questions asked}

I copied down all questions that were asked verbatim as well as the verbal attempts at getting viewers to engage with the content or their peers. The majority of questions were rhetorical and asked learners to recall. Presenters responded to their own questions without pausing while some had the verbal habit of using tag questions and inserting OK or Alright into almost each sentence. In Figure 1, an extract of questions asked during a few consecutive minutes of transmission exemplifies the low mental processing requirements not to mention the lack of opportunity to respond.

- What's the implied request? Does Maru say..... ? No! What does too, double 0 mean? It means also, doesn't it?

- Do you remember that business of the pictures? Of course you do!

- Why did he laugh and laugh? I think because... .

- I seem to do nothing but ask you questions!

- I think I gave you the page, didn't I?

- Why does he think of himself as the "homeless foreign alien"? Where does he come from? Yes, you knew that! South Africa!

- Do you know that kind of situation where you ask somebody something and they say "Yes"? For example: Did you go to the movies last night? Yes. Well did you enjoy the film? Yes.

Figure. 1: Sample of presenter questions asked in consecutive minutes

Ironic too, is the presenter's awareness of asking many questions (bold type) and her perception that this was effective interaction.

\section{Vocal and verbal characteristics}

With the exception of Presenter 8, the others spoke a clear, unmarked English. All were articulate although one or two presenters should change their voice pitch and volume in order to emphasise key phrases. Some presumed an invitational or inclusive style to promote interaction:

- Let's do an example together as to why we need logs. We handled similar ones a couple of weeks ago but just to refresh your memory we are going to try one. On the screen in a few seconds you should be seeing a sum...

- Now are you sitting perfectly still like me? Do you have a velocity at the moment? I bet you all said no, of course I don't have a velocity, I'm not changing my displacement, I'm sitting here perfectly still. So you could say your velocity compared to the floor below you or compared to this table is zero.

Generally the tone was conversational but ever so often a pedantic or moralising tone of voice was evident, conveying more than the explicit message:

- Boys and girls, never fail to show all your calculations. We will go through your calculations to find marks and we will - You must show them clearly! Remember you have to show all your steps or else you won't get all ten marks! Right now, let's see! So this is the solution! Now look back!. 
- ... that's why I cannot urge you enough to read everything you can lay your hands on. Everything you can lay your hands on, it doesn't matter whether it's in English or in your mother tongue. To read is important - I would like you to make a kind of promise to yourself, "Yes I should read" not because it's better for your English, but because it's better for you.

In a genuine attempt to emphasise the importance of preparing well for the exams, some presenters may have heightened the affective filter with upsetting comments although they tried to add a humanising element by motivating learners and wishing them well.

\section{Speech slips}

Human fallibility resulted in several speech slips e.g. We always have an exclamation mark at the end to indicate that the information [read interjection] that has been made of let's say pain, Ouch! or pleasure Aaah! ... Obvious inaccuracies during explanations e.g. the presenter saying 2 but pointing to 4, or saying divide but using the multiplications sign were disconcerting. In Chemistry, one presenter repeatedly self-corrected: Alkines are double, sorry, these are triple. These slips may possibly have been due to nervousness, loss of concentration or illness ${ }^{4}$. One such inadvertent blunder led to a viewer calling in to point out the flaw. Two presenters soon converted this incident into a didactically debatable technique in order to encourage interaction: Something that I would like to share with you, simply that really works. If I make a mistake deliberately and sometimes not so deliberately, you do make negligent errors, they will immediately alert you to that and in that way you can see whether they are attending or not. I know the one time I did something, I actually made a mistake in one of the formulas, and somebody did call in and I was relieved. I was pleased because at least I knew there was a body out there... I would do something on screen and I would say afterwards "I think I've made a mistake here, can you help me?" Try and phone in....

\section{Use of subject jargon}

Another pertinent aspect of the presenters' formulation of a message, which was a possible impediment, was the assumption that learners were familiar with subject-specific concepts and jargon. To illustrate what this means, I offer an extract from a telelesson:

Right, what have we been doing? We have been looking at motion and we've been looking at a whole lot of words that describe motion like displacement, force, velocity, acceleration. We know that all of those are vector quantities and that if you say, have two displacements happening one after the other, if you draw them head to tail, they will have a single effect called the resultant displacement. Alright? The resultant of two displacements is the single displacement that has the same effect as those two acting together. And we've looked at resultant displacements and resultant veloci..., forces but we've never looked at that. So that is what we are going to look at, looking at a vector, as velocity as a vector quantity that can have a resultant. And I need you to imagine quite hard. Do you remember what velocity means? It's the rate of change in the displacement of a body, or if you like how much the displacement of a moving body changes in one second.

It is clear from the above explanation that if a learner is not familiar with these terms and experiences it as an incomprehensible presentation, it further decreases any chance of interaction.

4 In two separate broadcasts, presenters admitted on air to having influenza. 
This aspect of the content material could also have been discussed as part of language proficiency but I discuss it here, as there does not seem to be sufficient consensus that the lack of comprehension in parts relates to language issues rather than content. Furthermore, it ties in with the level of abstraction assumed by certain presenters. Presenters 2 and 7 were concerned about this matter and elaborate on their experiences of learners' struggle to comprehend in a traditional classroom situation:

- Now if you, particularly in English, if you give them some concepts and they don't understand them, they don't know how to ask about them. They don't know how to formulate a question in English because they are not sure what you are talking about. I suspect with a lot of them, in perhaps not English classes but in their content subject classes, if they lose a thread at the beginning of a class, they've lost it...

- Most of them, and I know because I'm coaching children from other schools. They just get a piece of paper called notes, saying displacement is bloody bla and then they're supposed to learn that off by heart, they don't learn, they memorise them. The word from then onwards is used in all lessons without any further explanations, and they don't understand what it meant. And I'm finding that the questions that I've been asked are all to do with very basic concepts.

Only two presenters did not consider their use of jargon to be problematic.

\section{Discussion}

Survey data indicated that $66.5 \%$ of TeleTuks viewers did have questions to ask and this was confirmed by interview data. So why did they then not ask? An unanticipated explanation was that no connection in the form of an available or operational telephone link existed at the origination site despite such a link being a prerequisite before a school was equipped. This technical barrier accounted for why several schools were not responding but was beyond the control of the presenter, for no matter how well interactive tasks may have been integrated into the instructional design, viewers would not have been able to give feedback given such technological limitations.

Good presenter explanations and full comprehension of the content by some viewers accounted for viewer satisfaction with the broadcasts and implied that these learners had no need to phone in. But although most presentations were skilfully executed and supported by visual cues, the essential dynamics of the teaching-learning dyad were missing: two-way dialogue. Passive viewer behaviour customarily associated with watching public television may have accounted for some lack of responsiveness, and I believe that the responsibility for initiating interaction lies primarily with the presenters (Barker, 1995; Kearsley, 1995; Laurillard, 1993; Van Zyl, 1996) who ought to have engaged viewers as co-participants of the instructional process. The common understanding among participants in a communication episode is that the source (presenter) allows for a response after message delivery, yet presenters did not create sufficient opportunities for phoning in; neither did they capitalise on other forms of interaction. This supports the analysis of teaching via ITV done by Oliver and McLoughlin (1997) that instructors underutilise opportunities afforded by the medium to assist cognitive interactions. Their study also revealed that instructors use the audio channel to give instructions and deliver content material in an explanatory one-way talk mode. Those questions that presenters posed "tended to be narrow and convergent, requiring little reflection of consideration on the part of the learner" (Zhang \& Fulford, 1994: 9). Drawing 
on the commercial ITV findings of Van Dijk and De Vos (2001) again, the one-sidedness they describe resembles TeleTuks Schools in that the supplier (the equivalent of the presenter in instructional ITV) not only takes responsibility for initiating interaction but also uses more of the total interaction time than does the consumer (learner). Borsook and Higginbotham-Wheat (1991) suggest that optimal interaction occurs when there is a balance of control between the two communicators. Although their study focused on adult learners and the computer, any imbalance in the locus of control diminishes interaction as mirrored in the tightly presentercontrolled TeleTuks scenario. My surmise is that in many instances, face-to-face instruction suffers from the same malady.

Although I did not approach this study from a pragmatic point of view, certain research findings suggested constructive strategies for improving future programmes by a change in practice i.e. the way in which presenters structure and present contents to remote learners. I here refer to the chunking of content and specifically to the term grain size as a key ingredient for instructional interaction. This concept denotes the length of time that a communicative sequence takes to complete before a next one can be initiated. By implication the longer it takes before a learner can interrupt or take action the less likely there is going to be interaction (Borsook \& Higginbotham-Wheat, 1991). Teleteachers may thus need to reconsider the rigid structure and very controlled presentation of their lessons since their current methodological approach does not encourage participation.

Apart from restructuring design, teleteachers need to hone interpersonal communication skills when students are not physically present, compare telephone tutoring (Pugliese, 2000)

Where instructor and learner are separated by distance, participatory activities (interaction) require careful planning and instructional design well in advance of the teaching situation (Kruh \& Murphy, 1990; MacKinnon, Walshe, Cummings, \& Velonis, 1995; Monson, 1978). By implication, teleteachers require a sound understanding of interaction as an instructional tool and should know how to design technology-mediated learning opportunities that entail more than just posing a question and awaiting an answer. Having said that, an underestimated element of communication is the use of what Barker (1995) terms, "structured silence" (p. 8). Effective use of this powerful instructional tool would allow learners to intra-act i.e. reflect and process in silence while engaged with content. Presenters did not pause sufficiently or were inclined to give instructions and then fill the silence with repetitive comments and distracting remarks. Furthermore, presenters need a well-grounded and coherent perspective on higher order thinking skills, methodology and using television as an effective teaching medium. Besides the importance of training and adapting for ITV, the optimal choice of instructor may lie in personality rather than experience and teaching expertise as Main and Riise (1995) suggest: "Distance learning may depend even more on instructor charisma and style than the traditional classroom in which case instructor characteristics are important to examine in terms of their effect on interaction" ( p. 11). Hardin (personal e-communication, 16 February 2004) too, believes that ultimately the deciding success factor for student participation and satisfaction is the presenter's personality. This variable also emerges as a possible research avenue.

An early proposition had been that the primary causal factor of poor interaction resided within the learners, in particular their English proficiency but despite their expressive skills being limited, it materialised that the presenter played a far greater role in orchestrating or oppressing 
interaction than initially realised. Although not discussed here, both educators and learners unanimously refuted cultural reticence as an explanation for poor participation. So, contrary to the initial supposition that guided this study, I established in answer to my research question, in descending order of influence, that

- presenter-related factors, rather than limited language proficiency, combined to ensure low reciprocity in the viewer audience.

- technological limitations and inadequate technician support, may have further contributed to low levels of interaction.

- learner inhibition had an influence, albeit limited, on participation rates.

Yet as I decoded the data at a complex level, the key findings revealed another dimension. I had clustered the various empirical findings from three categories that encompassed the viewer, presenter and context category into the following themes: Paradoxical perceptions, Presenter nescience, and Problematic practicalities and partnerships. A fine combing of these themes gave rise to a sense of mismatch or communicative noise. In several instances, the presenters' message was distorted in such a way by several factors that its delivery or decoding was not aligned to expectation. I not only pinpointed an unpredicted disparity between my initial propositions about why learners were not participating and the eventual findings but the data also indicated several facets that ought to have dovetailed neatly but which were at variance with each other. These discrepancies resulted in mismatches of expectations, needs and application and gave rise to my formulation of an instructional dissonance theory. By this I mean, instructional dissonance is the ignorance or denial of hindrances, barriers and distortions that permeate and negatively affect interpersonal communication between the instructor and student. Instructional communication is successful but not meaningful i.e. despite a carefully encoded message, which is sent untrammelled and also decoded (acknowledged) successfully, a mismatch of meaning (sense, utility) occurs. In order to start creating instructional equilibrium again, I underscore the importance of a meticulously encoded instructional message coupled with effective lesson design and apposite presenter behaviour during content delivery. In order to restore full balance, dynamics relating to the learners and technology also need consideration.

\section{Conclusion}

This inquiry revealed that presenters played the compounding role in stifling interaction and silencing learners. These presenter-related factors, rather than language proficiency, had combined to ensure low reciprocity in the viewer audience. Despite their teaching experience, meticulous preparation and good face-to-face track record, these presenters not only had a misconception of mediated interaction but also had insufficient background knowledge of the recipients of the message. The preconceptions that presenters held of the target audience's frame of reference, needs and level of proficiency resulted in, amongst others, a patronising attitude. Inadequate ITV lesson designs which require different strategies and resources, led to presenters creating few opportunities for synchronous interaction. Learning outcomes were not always clear and "interaction" limited to scores of rhetorical questions. Applicability of content being presented was questionable at times while implied time constraints also muted any potential attempts by learners to interact. Although diligent planning, thorough preparation and enthusiastic delivery were evident, the instructional message was not as well crafted as the presenters believed they had formulated it, resulting in instructional dissonance. Not only the 
formulation of the message but also the presenter's speech personality in particular the lack of pauses and pacing, affected potential interaction negatively. This disconcerting discovery was contrary to my initial supposition that the reasons for poor interaction were inherent to the learners. The rate of learner participation during interactive TV lessons was not influenced by an isolated factor as originally conceived but rather a combination of variables. Although these variables influenced certain broadcasts singly, the ITV presenter as initiator of communication played the weighted role overall regarding the lack of interaction.

This inquiry has highlighted communication barriers as intrusive noise elements of instructional communication and has enhanced understanding of the role of a presenter to facilitate interaction during televised instruction as implemented in a developing country context. Ostendorf's (1989) view suffices: Interactive televised instruction offers a means to carry knowledge to the ends of the earth. It is our job to be sure that instruction is educationally sound, and that it makes the most of its delivery mode (p. 95). We thus need to persevere in our quest to perfect interaction in teaching and learning contexts, with particular reference to those mediated by technology, since not only does the medium of television in a developing country have unique, instructional potential but ultimately all effectual learning may be influenced by effective instructional communication.

\section{REFERENCES}

Barker, B.O. 1995. Strategies to ensure interaction in telecommunicated distance learning. ACSDE Research Monograph, 12, 5-12.

Berlo, D.K. 1960. Process of communication: an introduction to theory and practice. Holt, Rinehart and Winston.

Borsook, T.K., \& Higginbotham-Wheat, N. 1991. Interactivity: What is it and what can it do for computerbased instruction? Educational Technology, 31(10), 11-17.

Burrell, M., \& Morgan, M. 1979. Sociological paradigms and organizational analysis. London: Heinemann.

Du Plooy-Cilliers, F., \& Olivier, M. 2001. Let's talk about interpersonal communication. Sandton: Heinemann.

Edirisingha, P. 1999. Open and distance learning for basic and non-formal education in developing countries. Paper presented at the Pan-Commonwealth Forum on Open Learning, Brunei.

Fulford, C.P., \& Zhang, S. 1993. Perceptions of interaction: the critical predictor in distance education. The American Journal of Distance Education, 7(3), 8-21.

Hyde, S.W. 1979. Television and radio announcing (3 ed.). Boston: Houghton Mifflin.

Kearsley, G. 1995. The nature and value of interaction in distance learning. Paper presented at the Distance Education Symposium \#3: Course Design, Pennsylvania.

Kruh, J.J., \& Murphy, K.L. 1990. Interaction in teleconferencing - the key to quality instruction. Paper presented at the 12th Annual Rural and Small Schools Conference, Kansas State University, Manhattan.

Laurillard, D. 1993. Balancing the media. Journal of Educational Television, 19(2), 81-93.

Lyons, C.M., MacBrayne, P., \& Johnson, J.L. 1994. Interactive television as a vehicle for the delivery of higher education to rural areas. Journal of Educational Technology Systems, 22(3), 205-211.

MacKinnon, A., Walshe, B., Cummings, M., \& Velonis, U. 1995. An inventory of pedagogical considerations for interactive television. Journal of Distance Education, 10(1), 75-94.

Main, R.G., \& Riise, E. 1995. A study of interaction in distance learning (interim technical report No. 
AL/HR- TP-1994-0037). Chico, California: California State University.

McHenry, L., \& Bozik, M. 1995. Communicating at a distance: a study of interactions in a distance education classroom. Communication Education, 44(4), 362-371.

Monson, M. 1978. Bridging the distance - an instructional guide to teleconferencing. Wisconsin: Wisconsin University.

Oliver, R., \& Grant, M. 1995. Interactive broadcast television in Australia. Journal of Educational Television, 21(1), 37-50.

Oliver, R., \& McLoughlin, C. 1997. Interaction patterns in teaching and learning with live interactive television. Journal of Educational Media, 23(1), 7-24.

Ostendorf, V.A. 1989. Teaching through interactive television - a practical introduction to business television and distance education developed for traditional instructors. Colorado: Virginia A. Ostendorf.

Pugliese, C. 2000. Hold the line: telephone lessons in France. IATEFL Issues (157), 2.

Sedibe, E.M., \& Evans, R. 1999. TeleTuks policy document for schools and sponsors. Pretoria: University of Pretoria.

Shrestha, G. 1997. A review of case studies related to distance education in developing countries. Retrieved 9 January, 2003, from http://www.undp.org/info21/public/review/pb-revme.html

Van Dijk, J.A.G.M., \& De Vos, L. 2001. Searching for the Holy Grail - images of interactive television. New Media and Society, 3(4), 443-465.

Van Zyl, J. 1996. The use of interactive television for education: a South African perspective. Communication, 22(1), 90-97.

Zhang, S., \& Fulford, C. P. 1994. Are interaction time and psychological interactivity the same thing in the distance learning television classroom? Educational Technology, 34(6), 58-64.

\section{ABOUT THE AUTHOR}

\section{Rinelle Evans}

Faculty of Education

School for Teacher Training

University of Pretoria

Pretoria

0003

Email: revans@postino.up.ac.za 